\title{
EXCESS MORTALITY IN GENERAL HOSPITAL PATIENTS WITH DELIRIUM: A 5-YEAR FOLLOW-UP OF 519 PATIENTS SEEN IN PSYCHIATRIC CONSULTATION
}

\author{
Albert M. van Hemert, ${ }^{*}$ Rose C. van der Mast, $\dagger$ Michiel W. Hengeveld* and \\ MARIELLE VORSTENBOSCH ${ }^{\dagger}$
}

(Received 17 June 1993; accepted in original form 21 October 1993)

\begin{abstract}
Mortality was determined in 519 patients with delirium who were seen in psychiatric consultation in two general hospitals. Among 419 patients with simple delirium (DSM-III: 293.00) in-hospital mortality was $26 \%$. As compared to average hospital patients the age adjusted in-hospital excess mortality ratio varied from 6.2 for patients with malignancies to 2.1 for patients with motor system disease. After hospital discharge the 5-yr cumulative mortality was $51 \%$. As compared to the general population excess mortality was noted in most, but not in all diagnostic subgroups. The age and sex adjusted excess mortality ratio varied from 14.1 for malignancies to 1.3 for motor system disease. The figures underline a general notion that delirium may be an indicator of disorders of grave prognosis, but mortality appears to depend more on the medical condition than on the presence of delirium.
\end{abstract}

DeliRium is a transient organic mental disorder of acute onset, characterized by global impairment of cognitive functions, reduced consciousness, attentional abnormalities, altered motor activity, and a disordered sleep-wake cycle [1]. It is among the most common psychiatric disorders in general hospital in-patients. It has been estimated that 6 to $15 \%$ of all patients admitted to a general hospital experience an episode of delirium [1-5]. In the majority of studies of general hospital patients seen in psychiatric consultations the prevalence of delirium has been between 10 and $15 \%$ [6-9].

In the revised third edition of the Diagnostic and Statistical Manual (DSM-III-R) death is mentioned as one of the sequelae of delirium [10]. Indeed, many authors have reported high mortality rates in association with delirium [3, 7, 8, 11-14]. The reported in-hospital mortality ranges from 11 to $23 \%$ for patients with delirium who were seen in psychiatric consultations and from 8 to $65 \%$ for patients with delirium who were detected by screening $[3,11]$. In follow-up studies the reported mortality ranges from 14 to $38 \%$ in a period ranging from 6 months to $4 \mathrm{yr}$ after hospital discharge [11-14].

In most studies it remains unclear to what extent delirium is associated with excess mortality, because of a lack of comparison populations. In one study the in-hospital mortality was found to be $13 \%$ in patients with delirium as compared to $6 \%$ in controls matched for age, sex and primary medical diagnosis [13]. In another study of elderly patients in-hospital mortality was $8 \%$ for delirious patients and $1 \%$ for unmatched hospital controls. In this study the relative risk of dying was 1.8 in the first 6 months after hospital discharge [11].

*Department of Psychiatry, Leiden University Hospital

†Department of Psychiatry, Dijkzigt University Hospital, Rotterdam.

Address correspondence to: Albert M. van Hemert, M.D., Department of Psychiatry, Out-patient Clinic, Leiden University Hospital, Building 1 B1-P, P.O. Box 9600, 2300 RC Leiden, The Netherlands. 
In the present study mortality was determined in 519 patients with delirium who were seen in psychiatric consultation on non-psychiatric wards of two university hospitals. Mortality during the admission in which the delirium occurred (in-hospital mortality) was compared to the average mortality in the two hospitals for patients of similar age. An attempt to match patients for medical diagnoses failed, bccausc patients with delirium presented with many more diagnostic codes than patients with no delirium and similar primary diagnoses. Instead, delirium patients were separated in subgroups of various medical diagnoses and within each subgroup mortality was compared to the age-adjusted average hospital mortality. After hospital discharge patients were followed for a period up to $5 \mathrm{yr}$. In this period mortality in the patients was compared to the average mortality in the general population for subjects of similar age and sex.

\section{METHOD}

In 1984 the Netherlands Consortium for Consultation Psychiatry started a registration of psychiatric consultations in several general hospitals in The Netherlands. For each psychiatric consultation the consultant completed a standard form with characteristics of the patient and consultation [15]. For the present study patients with a diagnosis of delirium were selected from the 1984-1988 registers of two university hospitals in Leiden and Rotterdam. In both hospitals DSM-III was used as the standard for psychiatric classification. Primarily, patients were selected if the main psychiatric diagnosis was delirium (DSM-III code: 293.00), dementia with delirium $(290.11,290.30$ and 290.41), alcohol withdrawal delirium (291.00) or delirium due to psychoactive substances (292.81). The main analyses focused on the largest homogeneous group of patients with DSM-III code 293.00.

For all patients that were identified data concerning mortality and medical condition was collected in 1992. Data concerning in-hospital mortality was obtained from the computerized hospital administration. Data concerning mortality after hospital discharge was obtained from the civil population registers. For each subject it was checked whether he or she was alive on the date of follow-up. For those who died the date of death was obtained. For each subject the individual time of follow-up was defined as the time between the date of hospital discharge and the first of three potential end-dates: (I) the date information about the survival status was obtained; (2) the date of death; or (3) the date of 5-yr survival. The individual follow-up periods were summed to a total observation time expressed in person-yr.

Data concerning the medical condition during the hospital admission in which the delirium occurred was obtained from the patient files and from the computerized hospital registration of medical diagnoses. In many patients more than one medical diagnosis was made. For these patients the analyses focused on the condition considered to be the primary reason for admission.

\section{Data-analysis}

The observed number of deaths in the study cohort was compared to the number of deaths in two reference populations. For the in-hospital mortality, all admissions in the period 1984-1988 in the two hospitals served as the reference population. The age and hospital specific mortality data was available from the hospital administration. For each hospital age specific mortality rates were calculated as the number of deaths over the number of admissions in 10-yr strata of age. The expected in-hospital mortality for the cohort was calculated in each age stratum as the number of patients multiplied by the stratum specific mortality rate. For the total group the expected mortality was calculated as the sum of the age specific numbers. The excess mortality ratio was defined as the ratio of the observed over the expected number of deaths. The figure represents an age-standardized relative risk of dying.

For the mortality after hospital discharge, the general population was chosen as the reference population. National age and sex specific mortality rates from 1986 were available from the Dutch Central Bureau for Statistics (CBS). For the study cohort that was alive at the time of hospital discharge the number of person-years of observation was calculated for $1 \mathrm{yr}$ strata of age and for the two sexes. The expected number of deaths during follow-up was calculated in strata of age and sex and summed to a total for the group. The excess mortality ratio (observed/expected) represents an age- and sex-standardized mortality rate ratio. This figure is better known as the Standardized Mortality Ratio (SMR) [16].

Excess mortality ratios in subgroups of medical diagnosis were calculated for the main classes of medical disorders only, because subgroups of separate diagnoses were too small. The $95 \%$ confidence interval (CI) of the ratio was approximated, assuming a poisson distribution for the observed number of deaths and no sampling variation for the expected number [17]. The 5-yr cumulative mortality was calculated in a life- 
table with strata of 6 months [16]. Patients who were withdrawn alive in a stratum were considered to be at risk for half the time of the particular interval. The $95 \%$ confidence interval was calculated according to Grecnwood as implemented in the Stata statistical software package [18].

\section{RESULTS}

In the study period 225,000 patients were admitted to the two hospitals. A psychiatric consultation was requested for 3674 patients, of whom $532(14 \%)$ had a delirium as main psychiatric diagnosis. Mortality data was not traced for six patients and medical data was not located for seven patients. These patients were excluded from the analyses, leaving 519 patients $(98 \%)$ for the analyses. The average age was $62.9 \mathrm{yr}$ (SD: $17.0 \mathrm{yr}$; range: $11-95 \mathrm{yr}$ ) and $65 \%$ were male. The psychiatric diagnoses were: $419(81 \%)$ delirium (DSM-III code: 293.00$), 30(6 \%)$ dementia with delirium $(290.11,290.30,290.41), 54(10 \%)$ alcohol withdrawal delirium $(291.00)$ and $16(3 \%)$ delirium due to psychoactive substances.

\section{In-hospital mortality (DSM-III code: 293.00 )}

Of the initial cohort of 419 delirium patients with DSM-III code 293.00, 108 patients died during the hospital admission $(26 \% ; 95 \% \mathrm{Cr}: 21.6-30.0 \%)$. On average, patients who died were older than patients who survived $(66.3 \pm 14.8$ vs $62.8 \pm 17.2$ yr) and males were slightly over-represented in the former group (70\% vs $63 \%$ ). Based on the average mortality figures of the two hospitals the expected number of deaths for a group of similar age was 23.9 , resulting in an in-hospital excess mortality ratio of 4.5 (95\% CI: $3.7-5.4)$.

In Table I the observed and expected number of deaths are presented in categories of the main medical diagnosis underlying delirium. Excess mortality was between 3.6 and 5.0 for most categories with the exception of malignancy (6.2) and motor system disease (2.1). In the vast majority of the diagnostic entities listed the observed number of deaths in patients with delirium was higher than the expected number for the average hospital patient.

\section{Mortality during follow-up (DSM-III code: 293.00 )}

The cohort of patients who were alive at hospital discharge was followed for a period up to $5 \mathrm{yr}$. For 311 patients with DSM-III code 293.00 the average follow-up period was 3.2 (SD: 1.9) years. The total time of observation amounted to 984.3 person-years. At the end of follow-up 149 patients had died. In Table II the risk of death after hospital discharge was calculated for consecutive periods of 6 months. The risk of death was highest in the first half year after discharge $(17 \%)$. In the period from 1 to $5 \mathrm{yr}$ after discharge the mortality risk demonstrated more or less random fluctuation between $3 \%$ and $8 \%$ each half year. The 5 yr cumulative mortality risk was $51 \%(95 \% \mathrm{CI}: 45-57 \%)$. At the time of discharge the patients who eventually died were 10 yr older than those who survived $(67.8 \pm 15.8$ vs $58.4 \pm 17.7 \mathrm{yr})$. Mortality was equally distributed over the sexes (62 and $60 \%$ males respectively).

For a cohort of similar age and sex the expected number of deaths in the average Dutch population was 41.3 . For the total cohort the excess mortality ratio was 3.6 $(95 \%$ CI: 3.04 .2$)$. Excess mortality was especially high in the first year after discharge. 
TABLE I.-MORTALITY IN 419 PATIENTS WITH DELIRIUM (DSM-III CODE: 293.00) DURING HOSPITAL ADMISSION IN CATEGORIES OF THE MAIN SOMATIC DIAGNOSTIC CATEGORY AS COMPARED TO THE AGE- AND HOSPITAL-ADJUSTED EXPECTED MORTALITY IN THE AVERAGE POPULATION OF THE TWO HOSPITALS FROM WHICH THE PATIENTS WERE SELECTED

\begin{tabular}{|c|c|c|c|}
\hline & $N$ & Death $(E)$ & $O / E(95 \% \mathrm{Cl})$ \\
\hline $\begin{array}{l}\text { Oro-pharyngeal } \\
\text { Gastro-intestinal } \\
\text { Haematological } \\
\text { Lung } \\
\text { Other } \\
\text { Subtotal }\end{array}$ & $\begin{array}{l}12 \\
22 \\
21 \\
11 \\
32 \\
98\end{array}$ & $\begin{array}{rr}6 & (0.98) \\
6 & (1.22) \\
6 & (0.63) \\
4 & (0.56) \\
9 & (1.59) \\
31 & (4.99)\end{array}$ & $6.2(4.2-8.6)$ \\
\hline $\begin{array}{l}\text { Cardiovascular disease } \\
\text { Myocardial infarction } \\
\text { Coronary artery surgery } \\
\text { Valve disease } \\
\text { Cardiac congestion } \\
\text { Aorta disease } \\
\text { Peripheral vascular disease } \\
\text { Other } \\
\text { Subtotal }\end{array}$ & $\begin{array}{l}22 \\
19 \\
11 \\
17 \\
26 \\
14 \\
15 \\
124\end{array}$ & $\begin{aligned} 13 & (1.19) \\
2 & (1.13) \\
2 & (0.55) \\
3 & (0.88) \\
5 & (1.80) \\
6 & (0.99) \\
5 & (0.63) \\
36 & (7.17)\end{aligned}$ & $5.0(3.5-6.8)$ \\
\hline $\begin{array}{l}\text { Respiratory disease } \\
\text { Chronic obstructive lung disease } \\
\text { Other } \\
\text { Subtotal }\end{array}$ & $\begin{array}{r}11 \\
8 \\
19\end{array}$ & $\begin{array}{ll}3 & (0.70) \\
2 & (0.42) \\
5 & (1.12)\end{array}$ & $4.5(1.4-9.3)$ \\
\hline $\begin{array}{l}\text { Motor system disease } \\
\text { Fractures trunk and extremities } \\
\text { Head trauma } \\
\text { Other } \\
\text { Subtotal }\end{array}$ & $\begin{array}{l}25 \\
14 \\
13 \\
52\end{array}$ & $\begin{array}{ll}5 & (2.08) \\
0 & (0.38) \\
2 & (0.82) \\
7 & (3.28)\end{array}$ & $2.1(0.8-4.1)$ \\
\hline $\begin{array}{l}\text { Gastrointestonal disease } \\
\text { Haemorrhage/perforation/obstruction } \\
\text { Liver cirrhosis/pancreatitis } \\
\text { Other } \\
\text { Subtotal }\end{array}$ & $\begin{array}{r}8 \\
11 \\
14 \\
33\end{array}$ & $\begin{array}{ll}\mathrm{l} & (0.42) \\
6 & (0.47) \\
1 & (1.10) \\
8 & (1.98)\end{array}$ & $4.0(1.7-7.4)$ \\
\hline $\begin{array}{l}\text { Neurological disease } \\
\text { Cerebral vascular accident } \\
\text { Seizure/Guillain B./M. Parkinson } \\
\text { Other } \\
\text { Subtotal }\end{array}$ & $\begin{array}{r}10 \\
9 \\
11 \\
30\end{array}$ & $\begin{array}{ll}2 & (0.36) \\
2 & (0.48) \\
3 & (0.58) \\
7 & (1.42)\end{array}$ & $4.9(1.9-9.4)$ \\
\hline $\begin{array}{l}\text { Various } \\
\text { Ocular disease } \\
\text { Endocrine disorder } \\
\text { Renal disorder } \\
\text { Urinary tract disorder } \\
\text { Gynecological disease } \\
\text { Other } \\
\text { Subtotal }\end{array}$ & $\begin{array}{r}5 \\
10 \\
12 \\
5 \\
6 \\
25 \\
63\end{array}$ & $\begin{array}{rr}0 & (0.51) \\
3 & (0.68) \\
3 & (0.69) \\
1 & (0.39) \\
0 & (0.31) \\
7 & (1.36) \\
14 & (3.94)\end{array}$ & $3.6(1.9 \cdot 5.7)$ \\
\hline Total & 419 & $108(23.89)$ & $4.5(3.7-5.4)$ \\
\hline
\end{tabular}

$E=$ Expected number of deaths given age and hospital.

$O / E=$ Ratio of observed and expected deaths.

$95 \% \mathrm{CI}=95 \%$ confidence interval.

The observed number of deaths was 78 and the expected number 10.5, resulting in an excess mortality ratio of 7.4 (95\% CI: $5.8-9.2)$. In the period from one to five years of 
TABLE II. - MORTALITY RISK IN 311 PATIENTS WITH DELIRIUM (DSM-III CODE: 293.00) IN 6 MONTHS PERIODS AFTER HOSPITAL DISCHARGE

\begin{tabular}{lcccccc}
\hline $\begin{array}{l}\text { Months } \\
\text { after } \\
\text { discharge }\end{array}$ & $\begin{array}{c}\text { Number at } \\
\text { begin of } \\
\text { interval }\end{array}$ & $\begin{array}{c}\text { Withdrawn } \\
\text { alive in } \\
\text { interval }\end{array}$ & $\begin{array}{c}\text { Average } \\
\text { at risk }\end{array}$ & Deaths & $\begin{array}{c}\text { Mortality } \\
\text { risk per } \\
\text { interval }\end{array}$ & $\begin{array}{c}\text { Cumulative } \\
\text { mortality }\end{array}$ \\
\hline $0-5$ & 311 & 0 & 311 & 52 & 0.17 & 0.17 \\
$6-11$ & 259 & 0 & 259 & 26 & 0.10 & 0.25 \\
$12-17$ & 233 & 0 & 233 & 9 & 0.04 & 0.28 \\
$18-23$ & 224 & 3 & $222 \frac{1}{2}$ & 8 & 0.04 & 0.31 \\
$24-29$ & 213 & 0 & 213 & 11 & 0.05 & 0.34 \\
$30-35$ & 202 & 1 & 2011 & 7 & 0.03 & 0.36 \\
$36-41$ & 194 & 6 & 191 & 7 & 0.04 & 0.39 \\
$42-47$ & 181 & 21 & 1701 & 13 & 0.08 & 0.43 \\
$48-53$ & 147 & 22 & 136 & 7 & 0.05 & 0.46 \\
$54-59$ & 118 & 22 & 107 & 9 & 0.08 & 0.51 \\
\hline
\end{tabular}

follow-up the observed number of deaths was 71 and the expected number was 42.2 . The excess mortality ratio was 1.7 (95\% CI: 1.3-2.1).

In Table III the observed and expected number of deaths are presented in categories of the main medical diagnosis during hospital admission. Excess mortality ratio after discharge was particularly high in the subgroup of patients with malignancies (14.1), where as in the subgroup with motor system disease no substantial excess mortality was demonstrated (1.3). The excess mortality ratio was comparatively low in patients with gastrointestinal disorders.

\section{Mortality in patients with other types of delirium}

Due to the lower number of patients mortality in delirium types other than DSMIII code 293.00 were analysed in less detail. In thirty patients delirium was related to dementia and in seventy patients delirium was related to alcohol withdrawal or psychoactive substance use. The first group was considerably older $(74.9 \pm 13.3 \mathrm{yr})$ than the latter $(52.6 \pm 15.6)$. Males were more frequent in the substance related $(76 \%)$ than in the dementia related group $(47 \%)$. For both groups in-hospital mortality was comparatively low, but mortality during follow-up was similar or even increased as compared to other delirium patients. Of patients with dementia related delirium six died during the hospital admission and eighteen died during follow-up. The expected numbers were 2.4 and 4.0 respectively, resulting in excess mortality ratios of 2.5 and 4.5. Of patients with substance related delirium six died during admission and twentyfive during follow-up. The expected numbers were 2.5 and 3.8 respectively, resulting in excess mortality ratios of 2.4 and 6.6. In both groups of patients malignancies and cardiovascular disease were under-represented and gastrointestinal, neurological and other diseases were over-represented as compared to the other patients with delirium.

\section{DISCUSSION}

The mortality in 519 general hospital patients with delirium was quantificd with reference to specified comparison groups. Both during the initial hospital admission 
TABLE III. - MORTALITY IN 311 PATIENTS WITH DELIRILM (DSM-III CODE: 293.00) I)URING $1-5$ YR OF FOLLOW-UP IN CATEGORIES OF THE MAIN SOMATIC DIAGNOSTIC (ATEGORY AS (OMPARFD TO THE AGI:- ANI) SEX-ADJLSTED EXPECTED MORTALITY IN THE. GENERAL POPULATION

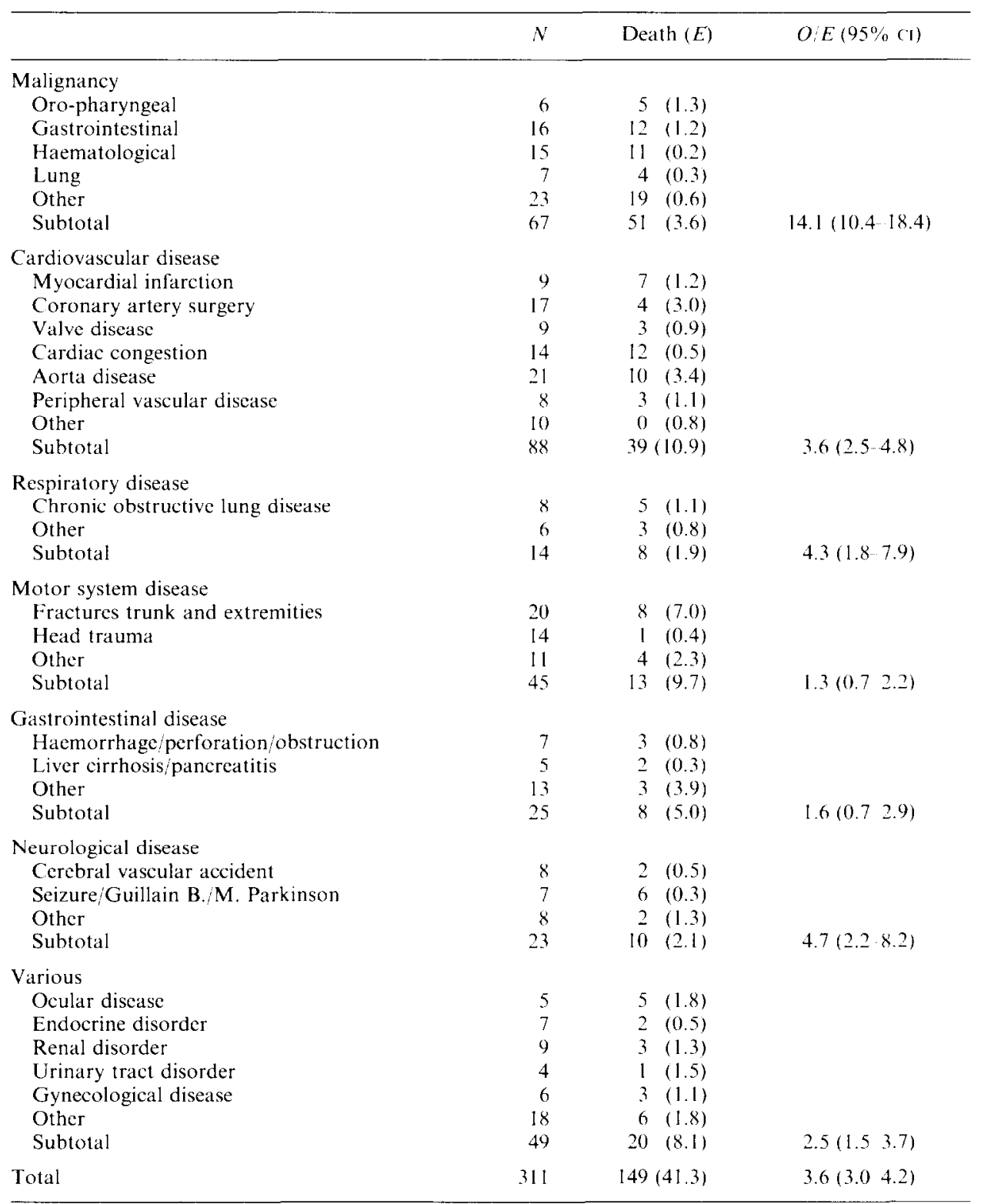

$E=$ Expected number of deaths given age and sex.

$O / E=$ Ratio of observed over expected number of deaths. $95 \% \mathrm{CI}=95 \%$ confidence interval

and during a $5 \mathrm{yr}$ period of follow-up considerable excess mortality was demonstrated. However, in various medical diagnostic subgroups substantial variation in excess mortality was noted. 
In-hospital mortality of patients with delirium was compared to average in-hospital mortality of patients of similar age. An advantage of this control condition is that it is reasonably well defined and data is readily available. An important disadvantage is that the average hospital patients, obviously, will not be similar to the patients with delirium with respect to the medical diagnosis. The occurrence of delirium will be more frequent in some disorders than in others and it is not unlikely that the prognosis of disorders related to delirium is more severe on average. It was expected, however, that subgroups of delirium patients with disorders of poor prognosis, such as malignancies and cardiovascular disease would present with excess mortality, while patients with less severe disorders such as motor system disease were expected to exhibit low mortality as compared to average hospital patients. The finding of excess mortality in each of the diagnostic subgroups might suggest that the presence of delirium, at least in psychiatric consultation patients, signifies a serious course of disease, even in patients with medical disorders that might be expected to have a fair prognosis in general.

Mortality during follow-up was compared to age and sex adjusted mortality in the general population. For patients suffering from curable disorders, it was expected that at some time after hospital discharge mortality risk would return to the average population level. Indeed, it appeared that for conditions that might be expected to have a good prognosis, i.e. motor system disease, no substantial excess mortality was noted during follow-up. Apparently, the occurrence of delirium during admission did not substantially affect the mortality risk after hospital discharge in these patients.

As in most other studies of patients with delirium, our study was limited to patients who were seen in psychiatric consultation. Obviously, these patients constitute only a small minority of all general hospital patients experiencing a delirium. The prevalence of delirium will vary from one hospital to another, but a prevalence of $6 \%$ of all admission is among the low estimates for a general hospital. This figure suggests that in our hospitals at least 7500 patients had a delirium in the study period. Of these only $532(7 \%)$ were seen in our study. If the self-limiting nature of many delirium episodes is taken into account, it may not be surprising that only a limited number of these patients will be seen by a psychiatrist. In addition, it is our experience that some physicians know how to handle patients with delirium without psychiatric interference and delirium is not always noted by the physician. Little is known about factors determining whether for a patient with delirium a psychiatric consultation is requested. Most likcly these are patients who are posing problems on the ward, but it is unclear to what extent such factors are related to mortality. In one study, where patients were identified by a screening procedure, a very high in-hospital mortality of $65 \%$ was demonstrated [3]. In another study of similar design among elderly patients in-hospital mortality was only $8 \%$ [11]. Further study of selection characteristics of patients with delirium being seen in psychiatric consultation, seem to be implicated to resolve this issue.

Our classification of patients in categories of medical diagnoses had important limitations. The retrospective classification could only rely on information being present in the medical records and hospital computer system. Access to the patient or the treating physician was no longer possible at the time of the study. This was a particular problem, because in many patients more than a single diagnosis had been made. The classification was hampered both by the complicated nature of a single 
disease process in some patients, and by co-occurrence of multiple disorders in others. Although the classification focussed on the primary disorder for which the patient was admitted, it could not be avoided that the resulting classification represents a significant simplification of the complicated medical conditions the patients with delirium presented with.

It seems reasonable to conclude that general hospital patients with delirium frequently suffer from medical disease of which delirium is but one of the complications. Our data suggest that in-hospital mortality is high, even in patients with less severe primary medical disorders. The outcome during the follow-up period appeared to depend more on the underlying condition than on the presence of delirium.

\section{REFERENCES}

1. Lipowski ZJ. Delirium: Acute Confusional States. Oxford: Oxford University Press, 1990.

2. Deshrande SN, Sundaram KR. Wig NN. Psychiatric disorders among medical in-patients in an Indian hospital. Br J Psychiatry 1989; 154: 504509.

3. Thomas RI, Cameron DP, HaHs MC. A prospective study of delirium and prolonged hospital stay. Arch Gen Psychiatry 1988; 45: 937-940.

4. Feldman E, Mayou R, Hawton K, Ardekn M, Smith Ebo. Psychiatric disorders in medical inpatients. $Q J \mathrm{Med}$ 1987: 63: 405-412.

5. Levkoff S, Cleary P, Liptzin B, Evans DA. Epidemiology of delirium: an overview of research issues and findings. Int Psychogeriatrics 1991; 3: 149-167.

6. Sirols F. Delirium: 100 cases. Can J Psychiatry 1988; 33: 375-378.

7. Trzepacz PT, Teague GB, Lipowski ZJ. Delirium and other organic mental disorders in a gencral hospital. Gen Hosp Psychiatry 1985; 7: 101106.

8. Weddington WW. The mortality of delirium: an underappreciated problem? Psychosomatics 1982; 23: $1232-1235$.

9. Stewart MA. Tlason VB, GuzF SB, Satterfield JH. A study of psychiatric consultations in general hospital. J Chron Dis 1962; 15: 331-340.

10. American Psychiatric Association. Diagnostic and Statistical Manual of Mental Disorders, Third Fdn, revised, pp. 100-103. Washington: American Psychiatric Association, 1987.

11. Francis J, Martin D, Kapoor WN. A prospective study of delirium in hospitalized elderly. JAMA 1990; 263: 1097-1101.

12. Rabins PV, FolsteIN MF. Delirium and dementia: diagnostic criteria and fatality rates. $\mathrm{Br} J$ Psychiatry 1982; 140: $149 \cdots 153$.

13. GuzE SB. Organic brain syndromes. Prognostic significance in general medical patients. Arch Gen Psychiatry 1967; 17: 365-366.

14. GUZE SB, CANTwEll DP. The prognosis in 'organic brain' syndromes. Am J Psychiatry 1964; 120: $878-881$.

15. Hengeveld MW, Huyse FJ, van der Mast RC, Tuinstra Cl. A proposal for standardization of psychiatric consultation-liaison data. Gen Hosp Psychiatry 1988; 10: 410.422.

16. KahN HA, Sempos CT. Statistical Methods in Epidemiology. Oxford: Oxford Liniversity Press, 1989.

17. VANDENBROLCKE JP. A short-cut method for the calculation of the 95 per cent confidence interval of the standardized mortality ratio. Am J Epidemiol 1982; 115: 303 - 304.

18. Computing Resource Centre. Stata Reference Manual: Release 3. Fifth Edn. Santa Monica: Computing Resource Centre, 1992. 